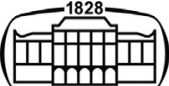

AKADÉMIAI KIADÓ

UNIVERSITY Of DEBRECEN

\section{International Review of Applied Sciences and Engineering}

$12(2021) 3,211-221$

DO1:

$10.1556 / 1848.2021 .00193$

(c) 2021 The Author(s)

\section{ORIGINAL RESEARCH} PAPER

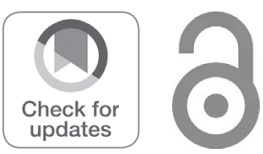

\title{
Adaptive backstepping control design for ball and beam system
}

\author{
Ayad Q. Al-Dujaili ${ }^{1 *} \odot$, Amjad J. Humaidi ${ }^{2}$, \\ Daniel Augusto Pereira ${ }^{3} \odot$ and Ibraheem Kasim Ibraheem ${ }^{4}$ \\ ${ }^{1}$ Electrical Engineering Technical College, Middle Technical University, Baghdad, Iraq \\ ${ }^{2}$ Control and Systems Engineering Department, University of Technology, Baghdad, Iraq \\ ${ }^{3}$ Department of Automatics (DAT), Federal University of Lavras (UFLA), Lavras-MG, Brazil \\ ${ }^{4}$ Department of Electrical Engineering, College of Engineering, University of Baghdad, Baghdad, Iraq
}

Received: October 14, 2020 • Accepted: April 10, 2021

Published online: June 16, 2021

\begin{abstract}
Ball and Beam system is one of the most popular and important laboratory models for teaching control systems. This paper proposes a new control strategy to the position control for the ball and beam system. Firstly, a nonlinear controller is proposed based on the backstepping approach. Secondly, in order to adapt online the dynamic control law, adaptive laws are developed to estimate the uncertain parameters. The stability of the proposed adaptive backstepping controller is proved based on the Lyapunov theorem. Simulated results are presented to illustrate the performance of the proposed approach.
\end{abstract}

\section{KEYWORDS}

ball and beam system, adaptive control, backstepping control

\section{INTRODUCTION}

A vast majority of the real systems, simple or complex ones, are nonlinear and a feedback controller can be a useful strategy to guarantee adequate performance [1]. Different systems that are inherently nonlinear have been adopted with academic purposes in order to study feedback control in graduate and undergraduate courses. The ball and beam is a classic example of such system that can be used as benchmark.

In the literature, a great diversity of methods can be found applied to this system [2-28]. In [2], disturbance rejection was reached by an active control approach for the ball and beam. In [3], Linear Quadratic Regulator (LQR) based optimal control design was derived. In [4], the dynamic model of the ball and beam nonlinear system was derived and its characteristics were extensively evaluated in simulations. The nonlinear backstepping control synthesis was considered in [5]. In [6], backstepping and Sliding Mode Control (SMC) were applied with a new proposed strategy that guaranties robustness. In [7], the aim was the application of different control schemes to the problem of ball and beam stabilization. Nonlinear factor and coupling effect were discussed in [8], both in model-free and model-based strategies. In [9], state feedback control was applied for the ball and beam, but considering the equations for its centrifugal force and applying them for the derivation of an adaptive control law. In [10], balance control was solved with an adaptive fuzzy control approach that considered also a classical strategy for dynamic surface control. In [11], there were adopted two control loops with PID rules that were adjusted by an optimization technique aiming at robustness, which was guaranteed by a particle swarm algorithm. In [12], an intelligent controller was proposed for the nonlinear ball and beam system and its performance was evaluated by a comparison with a classical conventional controller and a modern based one. 
SMC, both in its static and dynamic configurations, was applied in [13] considering simplifications in the ball and beam nonlinear dynamic model. In [14], a SMC method was proposed that utilizes the Jacobian for the linearization of the system. In [15], an integral SMC approach was employed for the control design of ball and beam system. In [16], the aim was a comprehensive comparative study for the tracking control of ball and beam system and the control input was designed via four SMC strategies, i.e., conventional first order, second order (super twisting), fast terminal, and integral. In [17], the control problem was solved in two steps in order to provide a synchronized control. A PD controller was applied for exact compensation and a neural network controller was applied for a nonlinear approximation. Improvements in system stability were studied in [18], where an Extended Kalman Filter (EKF) was adopted for the estimation of the weights of a neuro-controller.

In [19], input-output linearization of the dynamic system model was treated by a new approximation method. In [20], the modeling of a two degrees-of-freedom (DOF) ball and beam was presented in a decoupled manner, allowing the application of decoupled single-DOF controllers, one for the motor position and another for the ball position. In [21], fuzzy control was applied considering a genetic algorithm to optimize the design of a cascade controller. Despite being a simple system, the ball and beam nonlinear dynamics requires relatively complex models, motivating model-free control approaches such as fuzzy control [22] that avoid the application of linearization techniques. In [22], a fuzzy controller was applied, but in PD cascade structure and with optimization given by a particle swarm algorithm. In [23], cascade structures of PD and fuzzy controllers were also applied to the ball and beam nonlinear system.

In [24], an observer-based nonlinear velocity controller was proposed, with a transformation of coordinates applied in the design of the nonlinear observer that estimates the states of the ball and beam system. In [25], a nonlinear discrete-inverse optimal control approach was proposed to deal with the problem of the state variables regulation in the ball and beam system. In [26], a solution was proposed to the positioning problem for one degreeof-freedom ball-beam systems without using exact plant information by adopting the pole-zero cancellation technique for both the observer and controller. In [27], remote experimentation with the ball and beam was proposed as $n$ didactic methodology. Proportional-Integral-Derivative (PID) controller was tuned by the Non-dominated Sorting Genetic Algorithm. The performance of this multi-objective optimization approach was compared with the robust Loop-Shaping method. In [28] a novel procedure was proposed to stabilize the ball and beam system by using the inverse Lyapunov approach in conjunction with the energy shaping technique.

However, there has been little discussion about uncertainty and robust control for ball and beam system. So, the main purpose of this paper is to investigate the robust control design based on adaptive backstepping control for the ball and beam system, considering parameters uncertainties. Thus, the main contribution of the present work can be summarized by

$\square$ Development of classical and adaptive control algorithms for the Ball and Beam system.

$\square$ Proof of asymptotic stability for both classical and adaptive controlled systems based on the Lyapunov theorem.

This paper takes the following structure. In Section 2, the dynamic model and state space representation of the ball and beam system are presented. Section 3 presents the strategy for the nonlinear backstepping control design. Section 4 is dedicated to the design of the proposed adaptive backstepping controller. In Section 5, a simulation study is given to verify the effectiveness of the proposed scheme. Conclusions are given in Section 6.

\section{BALL AND BEAM STATE-SPACE MODELING}

Figure 1 shows the picture of a didactic ball and beam equipment. It has mainly two parts: the rotary servo and ball beam unit. The rotary servo-based unit plays a key role to control the tilt angle of the beam in order to regulate the ball position [20]. This system has two degrees of freedom, the lateral movement of the ball represented by its position in the horizontal axis, and the vertical movement of the beam represented by the angle with the horizontal axis [29, 30]. The ball position is given by a sensor allocated at one end of the beam. The angle of the beam is adjusted by a torque provided by an actuator placed at the other end, where there is a connected axis. The information about the ball and beam system is well described in the Quanser document [31].

Using a motor to provide the necessary torque, the controller regulates the position of the ball. Nevertheless, this system is inherently unstable, because for a given beam angle the position of the ball is unlimited. This makes the ball and beam system particularly complex and vastly used to validate a myriad of control approaches.

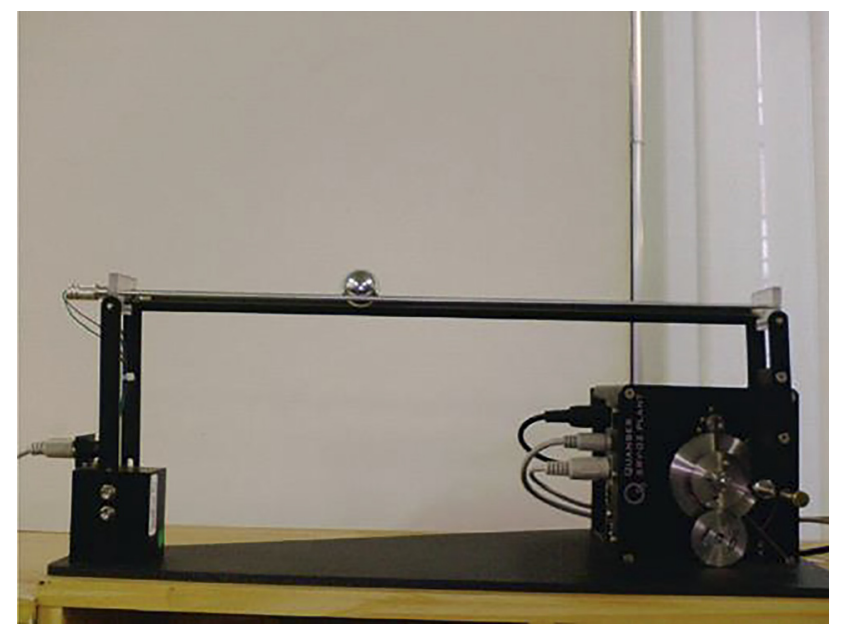

Fig. 1. Ball and beam [21] 
The equations describing the dynamics of the system can be obtained using Lagrange method, based on the energy balance of the system $[8,18]$, as follows

$$
\begin{gathered}
\left(\frac{I_{b}}{R^{2}}+m\right) \ddot{r}+m g \sin \theta-m r \dot{\theta}^{2}=0 \\
\left(m r^{2}+I+I_{b}\right) \ddot{\theta}+2 m r \dot{r} \dot{\theta}+m g r \cos \theta=u .
\end{gathered}
$$

where $m$ is the mass of the ball, $g$ is the acceleration of gravity, $I$ is the beam moment of inertia, $I_{b}$ is the ball moment of inertia, $R$ is the radius of the ball, $r$ is the position of the ball, $\theta$ the beam angle, $u$ is the torque applied to the beam.

The model can be described by the state space representation using the following state variables: $x_{1}$ for the ball position along the beam; $x_{2}$ for the ball velocity; $x_{3}$ for the beam angle; and $x_{4}$ for the beam angular velocity. As such, the generalized coordinates vector can be expressed by $\left[\begin{array}{llll}x_{1} & x_{2} & x_{3} & x_{4}\end{array}\right]^{T}=\left[\begin{array}{llll}r & \dot{r} & \theta & \dot{\theta}\end{array}\right]^{T}$. Consequently, the complete state space representation of the system is given by

$$
\begin{gathered}
\dot{x}_{1}=x_{2} \\
\dot{x}_{2}=\left(x_{1} x_{4}^{2}-g \sin \left(x_{3}\right)\right) / a \\
\dot{x}_{3}=x_{4} \\
\dot{x}_{4}=\left(u-2 x_{1} x_{2} x_{4}-g x_{1} \cos x_{3}\right) /\left(x_{1}^{2}+b\right)
\end{gathered}
$$

where

$a=\left(\frac{I_{b}}{m R^{2}}+1\right)$, and

$b=\left(I+I_{b}\right) / m$.

\section{BACKSTEPPING CONTROL DESIGN}

In this section, aiming to achieve of the control objective, we take a recursive technique, that can be understood as a natural variation of the well-known integrator backstepping strategy, to derive the dynamic control law of the regulation control problem [32-34].

The control objective is to actuate in the torque applied at the pivot of the beam, such that the ball can roll on the beam and achieve the regulation of the ball position. The torque causes a change in the beam angle and a movement in the position of the ball.

The algorithm of the backstepping requires a new definition of state variables, as follows

$$
\begin{gathered}
z_{1}=x_{1} \\
z_{2}=x_{2}-\alpha_{1}\left(z_{1}\right) \\
z_{3}=x_{3} \\
z_{4}=x_{4}-\alpha_{2}\left(z_{3}\right)
\end{gathered}
$$

where, $x_{2}, x_{4}$ are given by

$$
\begin{aligned}
& x_{2}=z_{2}+\alpha_{1}\left(z_{1}\right) \\
& x_{4}=z_{4}+\alpha_{2}\left(z_{3}\right)
\end{aligned}
$$

The backstepping algorithm is inspired by the one described in [32].

Now, taking the subsystem (7-12), the design procedure of the backstepping can be formulated. First, virtual control functions $\alpha_{i}(1 \leq i \leq n-2)$ must be considered in order to stabilize the subsystem. Based on the Lyapunov function, the dynamic control law is going to be derived on five steps, as follows.

Step 1: Considering the $z_{1}$ subsystem of system (7-12), and taking the time derivative of Eq. (7), we obtain

$$
\dot{z}_{1}=\dot{x}_{1} \text {. }
$$

Substituting (3) in (13), we obtain

$$
\dot{z}_{1}=x_{2} \text {. }
$$

Then, let $x_{2}=\alpha_{1}\left(z_{1}\right)$

$$
\dot{z}_{1}=\alpha_{1}\left(z_{1}\right)
$$

Let us choose $\alpha_{1}\left(z_{1}\right)$ as follows

$$
\alpha_{1}\left(z_{1}\right)=-c_{1} z_{1} \text {. }
$$

Then,

$$
\dot{z}_{1}=-c_{1} z_{1} \text {. }
$$

It is clear that Eq. (17) has exponentially stable characteristics, being $c_{1}>0$ a design parameter (chosen to be constant).

Step 2: Considering now the $\left(z_{1}, z_{2}\right)$ subsystem of system (7-12), we can rewrite Eq. (8) as follows

$$
z_{2}=x_{2}-\alpha_{1}\left(z_{1}\right) \text {. }
$$

Substituting (16) in (18), we can obtain

$$
z_{2}=x_{2}-\left(-c_{1} z_{1}\right)=x_{2}+c_{1} z_{1} .
$$

Now, we can rewrite (19)

$$
z_{2}=x_{2}+c_{1} x_{1}
$$

Step 3: Considering the $\left(z_{1}, z_{2}, z_{3}\right)$ subsystem of system (7$12)$, then taking the time derivative of Eq. (9), we obtain

$$
\dot{z}_{3}=\dot{x}_{3} \text {. }
$$

Substituting (5) in (21), we can obtain

$$
\dot{z}_{3}=x_{4} \text {. }
$$

Then, let $x_{4}=\alpha_{2}\left(z_{3}\right)$

$$
\dot{z}_{3}=\alpha_{2}\left(z_{3}\right) \text {. }
$$

Let us choose $\alpha_{2}\left(z_{3}\right)$ as follows

$$
\alpha_{2}\left(z_{3}\right)=-c_{3} z_{3} .
$$

Then,

$$
\dot{z}_{3}=-c_{3} z_{3} \text {. }
$$

Equation (25) can be described as exponentially stable $c_{3}>0$ design parameter (chosen to be constant). 
Step 4: Considering the $\left(z_{1}, z_{2}, z_{3}, z_{4}\right)$ subsystem of system (7-12), we can rewrite Eq. (10) as follows

$$
z_{4}=x_{4}-\alpha_{2}\left(z_{3}\right)
$$

Substituting (24) in (26), we can obtain

$$
z_{4}=x_{4}-\left(-c_{3} z_{3}\right)=x_{4}+c_{3} z_{3}
$$

Now, we can rewrite (27)

$$
z_{4}=x_{4}+c_{3} x_{3}
$$

Step 5: In this last step, we must design $\alpha_{1}$ and $\alpha_{2}$ such that $z_{1}, z_{2}, z_{3}$ and $z_{4}$ goes to zero. Aiming this, a proper and positive definite function $V_{1}$ is taken as a Lyapunov candidate for the system $(7-12)$

$$
V_{1}\left(z_{1}, z_{2}, z_{3}, z_{4}\right)=\frac{1}{2} c_{1}^{2} z_{1}^{2}+\frac{1}{2} z_{2}^{2}+\frac{1}{2} c_{3}^{2} z_{3}^{2}+\frac{1}{2} z_{4}^{2}
$$

or,

$$
\begin{aligned}
V_{1}\left(z_{1}, z_{2}, z_{3}, z_{4}\right)= & \frac{1}{2} c_{1}^{2} x_{1}^{2}+\frac{1}{2}\left(x_{2}+c_{1} x_{1}\right)^{2}+\frac{1}{2} c_{3}^{2} x_{3}^{2} \\
& +\frac{1}{2}\left(x_{4}+c_{3} x_{3}\right)^{2} .
\end{aligned}
$$

Differentiating $V_{1}$ along the solutions of (7-12) gives

$$
\begin{aligned}
\dot{V}_{1}= & c_{1}^{2} x_{1} \dot{x}_{1}+\left(x_{2}+c_{1} x_{1}\right)\left(\dot{x}_{2}+c_{1} \dot{x}_{1}\right)+c_{3}^{2} x_{3} \dot{x}_{3}+\left(x_{4}\right. \\
& \left.+c_{3} x_{3}\right)\left(\dot{x}_{4}+c_{3} \dot{x}_{3}\right) .
\end{aligned}
$$

Substituting (3-6) in (31), we can obtain

$$
\begin{aligned}
\dot{V}_{1}= & 2 c_{1}^{2} x_{1} x_{2}+2 c_{3}^{2} x_{3} x_{4}+a\left(x_{2}+x_{1} x_{1}\right)\left(x_{1} x_{4}^{2}-g \sin \left(x_{3}\right)\right. \\
& +c_{1} x_{2}^{2}+\frac{\left(x_{4}+c_{3} x_{3}\right)}{\left(x_{1}^{2}+b\right)}\left(-2 x_{1} x_{2} x_{4}-g x_{1} \cos \left(x_{3}\right)\right) \\
& +\frac{\left(x_{4}+c_{3} x_{3}\right)}{\left(x_{1}^{2}+b\right)} u+c_{3} x_{4}^{2} .
\end{aligned}
$$

In order to apply the Lyapunov theorem, we can isolate $u$ in Eq. (32) and propose the following control law

$$
\begin{aligned}
u= & \frac{\left(x_{1}^{2}+b\right)}{\left(x_{4}+c_{3} x_{3}\right)}\left(-2 c_{1}^{2} x_{1} x_{2}-2 c_{3}^{2} x_{3} x_{4}-c_{1} x_{2}^{2}-c_{3} x_{4}^{2}\right) \\
& +2 x_{1} x_{2} x_{4}+g x_{1} \cos \left(x_{3}\right)-\frac{\left(x_{1}^{2}+b\right)}{\left(x_{4}+c_{3} x_{3}\right)}\left(a \left(x_{1} x_{4}^{2}\right.\right. \\
& \left.-g \sin \left(x_{3}\right)\right) .
\end{aligned}
$$

Substituting (33) in (32), we can conclude that

$$
\dot{V}_{1}=-c_{1} x_{2}^{2}-c_{3} x_{4}^{2}
$$

where $c_{1}>0$ and $c_{3}>0$ are design parameters. Thus, $\dot{V}_{1}$ is negative, proving that the control system $(7-12)$ is stable. The structure of the proposed scheme is shown in Fig. 2.

\section{ADAPTIVE BACKSTEPPING CONTROL DESIGN}

In practice, the control systems may be subjected to model uncertainties and disturbance inputs. For this reason, the backstepping controller must be made robust to these model

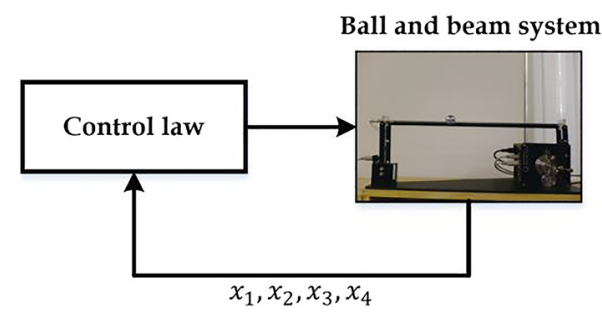

Fig. 2. Structure of the proposed backstepping control scheme

deviations. A common approach in robust controllers is to incorporate in the design some knowledge regarding the upper and lower bounds of the uncertainties and disturbances, guaranteeing a good performance for the worst-case problem. Nevertheless, this is a very conservative approach and will not be adopted in this work. Here, an adaptive control design will be proposed, in order to incorporate estimated values of the uncertainties in the control law [35-37].

The model can be represented in terms of uncertainties as follows

$$
\begin{gathered}
\dot{x}_{1}=x_{2} \\
\dot{x}_{2}=\left[\left(x_{1} x_{4}^{2}-g \sin \left(x_{3}\right)\right) / a\right]+d_{1} \\
\dot{x}_{3}=x_{4}
\end{gathered}
$$

$$
\dot{x}_{4}=\left[\frac{1}{\left(x 1^{2}+b\right)}\left(-2 x_{1} x_{2} x_{4}-g x_{1} \cos \left(x_{3}\right)+u\right)\right]+d_{2}
$$

where $d_{1}, d_{2}$ are uncertain items given by:

$d_{1}=\left(x_{1} x_{4}^{2}-g \sin \left(x_{3}\right)\right) / \Delta a$.

$d_{2}=\frac{1}{\left(x_{1}^{2}+\Delta b\right)}\left(-2 x_{1} x_{2} x_{4}-g x_{1} \cos \left(x_{3}\right)+u\right)$.

Now, we try to design the backstepping controller to the system in (35-38) with uncertainty, following a procedure that is similar to backstepping without uncertainty. First, we present the state equations including the uncertain terms

$$
\begin{gathered}
\dot{z}_{1}=-c_{1} z_{1} \\
\dot{z}_{2}=\left(x_{2}+c_{1} x_{1}\right)\left(\left[\left(x_{1} x_{4}^{2}-g \sin \left(x_{3}\right)\right) / a\right]+d_{1}+c_{1} x_{2}\right) \\
\dot{z}_{3}=-c_{3} z_{3} \\
\dot{z}_{4}=\left(x_{4}+c_{3} x_{3}\right)\left(\frac{1}{\left(x_{1}^{2}+b\right)}\left(-2 x_{1} x_{2} x_{4}-g x_{1} \cos \left(x_{3}\right)+u\right)\right. \\
\left.+d_{2}+x_{3} x_{4}\right)
\end{gathered}
$$

Let us choose the Lyapunov function (positive definite) as

$$
V_{2}\left(z_{1}, z_{2}, z_{3}, z_{4}\right)=\frac{1}{2} c_{1}^{2} z_{1}^{2}+\frac{1}{2} z_{2}^{2}+\frac{1}{2} c_{3}^{2} z_{3}^{2}+\frac{1}{2} z_{4}^{2}
$$

Equation (43) can be written as

$$
\begin{aligned}
V_{2}\left(z_{1}, z_{2}, z_{3}, z_{4}\right)= & \frac{1}{2} c_{1}^{2} x_{1}^{2}+\frac{1}{2}\left(x_{2}+c_{1} x_{1}\right)^{2}+\frac{1}{2} c_{3}^{2} x_{3}^{2} \\
& +\frac{1}{2}\left(x_{4}+c_{3} x_{3}\right)^{2} .
\end{aligned}
$$

Differentiating the function $V_{2}$ along the solutions of system (35-38) yields 


$$
\begin{aligned}
\dot{V}_{2}= & c_{1}^{2} x_{1} \dot{x}_{1}+\left(x_{2}+c_{1} x_{1}\right)\left(\dot{x}_{2}+c_{1} \dot{x}_{1}\right)+c_{3}^{2} x_{3} \dot{x}_{3}+\left(x_{4}\right. \\
& \left.+c_{3} x_{3}\right)\left(\dot{x}_{4}+c_{3} \dot{x}_{3}\right) .
\end{aligned}
$$

Substituting Eqs. (35-38) in Eq. (45), one can get

$$
\begin{aligned}
\dot{V}_{2}= & c_{1}^{2} x_{1} x_{2}+\left(x_{2}+c_{1} x_{1}\right)\left(\left[\left(x_{1} x_{4}^{2}-g \sin \left(x_{3}\right)\right) / a\right]+d_{1}\right. \\
& \left.+c_{1} x_{2}\right)+c_{3}^{2} x_{3} x_{4}+\left(x_{4}\right. \\
& \left.+c_{3} x_{3}\right)\left(\left[\frac{1}{\left(x 1^{2}+b\right)}\left(-2 x_{1} x_{2} x_{4}-g x_{1} \cos \left(x_{3}\right)+u\right)\right]\right. \\
& \left.+d_{2}+c_{3} x_{4}\right) .
\end{aligned}
$$

We can rewrite it as follows

$$
\begin{aligned}
\dot{V}_{2}= & 2 c_{1}^{2} x_{1} x_{2}+2 c_{3}^{2} x_{3} x_{4}+\left(x_{2}+x_{1} x_{1}\right)\left(\left[\left(x_{1} x_{4}^{2}\right.\right.\right. \\
& \left.\left.\left.-g \sin \left(x_{3}\right)\right) / a\right]+d_{1}+c_{1} x_{2}^{2}\right)+\frac{\left(x_{4}+c_{3} x_{3}\right)}{\left(x_{1}^{2}+b\right)}\left(-2 x_{1} x_{2} x_{4}\right. \\
& \left.-g x_{1} \cos \left(x_{3}\right)\right)+\frac{\left(x_{4}+c_{3} x_{3}\right)}{\left(x_{1}^{2}+b\right)} u+d_{2}+c_{3} x_{4}^{2} .
\end{aligned}
$$

\section{Control law:}

Now, we propose the following control law

$$
\begin{aligned}
u= & \frac{\left(x_{1}^{2}+b\right)}{\left(x_{4}+c_{3} x_{3}\right)}\left(-2 c_{1}^{2} x_{1} x_{2}-2 c_{3}^{2} x_{3} x_{4}-2 c_{1} x_{2}^{2}-2 c_{3} x_{4}^{2}\right) \\
& +2 x_{1} x_{2} x_{4}+g x_{1} \cos \left(x_{3}\right)-\frac{\left(x 1^{2}+b\right)}{\left(x_{4}+c_{3} x_{3}\right)}\left[\left(x_{1} x_{4}^{2}\right.\right. \\
& \left.\left.-g \sin \left(x_{3}\right)\right) / a\right]-\left(x_{1}^{2}+b\right) \tilde{d}_{2} \\
& -\frac{\left(x_{2}+c_{1} x_{1}\right)\left(x_{1}^{2}+b\right)}{\left(x_{4}+c_{3} x_{3}\right)} \tilde{d}_{1}
\end{aligned}
$$

where $\tilde{d}_{1}\left(\tilde{d}_{2}\right)$ represents the error between the actual uncertainty term $d_{1}\left(d_{2}\right)$ and the estimated uncertainty term $\widehat{d}_{1}$ $\left(\widehat{d}_{2}\right)$. Using (47), Eq. (46) becomes

$$
\dot{V}_{2}=-c_{1} x_{2}^{2}-c_{3} x_{4}^{2}+\left(x_{2}+c_{1} x_{1}\right) \tilde{d}_{1}+\left(x_{4}+c_{3} x_{3}\right) \tilde{d}_{2} .
$$

\section{Adaptive law:}

Let us choose the Lyapunov function as

$$
V_{3}=V_{2}+\frac{1}{2} \gamma_{1}^{-1} \tilde{d}_{1}^{2}+\frac{1}{2} \gamma_{2}^{-1} \tilde{d}_{2}^{2} .
$$

Taking the time derivative of the Lyapunov function and assuming stationary values of actual uncertainty terms leads to

$$
\begin{aligned}
\dot{V}_{3}= & \dot{V}_{2}+\gamma_{1}^{-1} \tilde{d}_{1} \dot{\hat{d}}_{1}+\gamma_{2}^{-1} \tilde{d}_{2} \dot{\hat{d}}_{2} \\
\dot{V}_{3}= & -c_{1} x_{2}^{2}-c_{3} x_{4}^{2}+\left(x_{2}+c_{1} x_{1}\right) \tilde{d}_{1}+\left(x_{4}+c_{3} x_{3}\right) \tilde{d}_{2} \\
& -\gamma_{1}^{-1} \tilde{d}_{1} \dot{\hat{d}}_{1}-\gamma_{2}^{-1} \tilde{d}_{2} \dot{\hat{d}}_{1} \\
\dot{V}_{3}= & -c_{1} x_{2}^{2}-c_{3} x_{4}^{2}+\gamma_{1}^{-1} \tilde{d}_{1}\left(\gamma_{1}\left(x_{2}+c_{1} x_{1}\right)-\dot{\hat{d}}_{1}\right) \\
& +\gamma_{2}^{-1} \tilde{d}_{2}\left(\gamma_{2}\left(x_{4}+c_{3} x_{3}\right)-\dot{\hat{d}}_{2}\right) .
\end{aligned}
$$

$$
\begin{aligned}
& \dot{\hat{d}}_{1}=\gamma_{1}\left(x_{2}+c_{1} x_{1}\right) \\
& \dot{\hat{d}}_{2}=\gamma_{2}\left(x_{4}+c_{3} x_{3}\right) .
\end{aligned}
$$

With this proposed adaptive law, the time derivative of the Lyapunov function become:

$$
\dot{V}_{3}=-c_{1} x_{2}^{2}-c_{3} x_{4}^{2} \leq 0 .
$$

According to the Barbalet theorem, $z_{1}, z_{2}, z_{3}$ and $z_{4} \rightarrow 0$ when $t \rightarrow \infty$, hence the system is asymptotically stable. The structure of the proposed adaptive backstepping controller scheme is shown in Fig. 3.

\section{SIMULATION RESULTS}

In order to validate the proposed control design procedure and verify its effectiveness, simulations are performed in MATLAB. The controlled system has been implemented within MATLAB/SIMULINK environment. The $\mathrm{m}$-function has been used to interface between the m-file and Simulink environment. The control and plant are coded inside $\mathrm{m}$-files, while these codes are called by their corresponding $\mathrm{m}$ function within SIMULINK Library. In order to give a better description of the simulations performed in Simulink/ MATLAB, we included a figure in Section 5 showing the Simulink block diagram (Figs 4 and 5). The results for the backstepping and adaptive backstepping designs will be presented for the regulation problem of the ball and beam system.

The parameters of the adaptive backstepping controller are selected as $c_{1}=0.1, c_{3}=0.7, \gamma_{1}=0.0001, \gamma_{2}=15$ and $\left[\begin{array}{llll}x_{1}(0) & x_{2}(0) & x_{3}(0) & x_{4}(0)\end{array}\right]=\left[\begin{array}{llll}0.1 & 0 & 1 & 1\end{array}\right]$.

Figure 6 shows the ball position, ball velocity, angle of the beam, angular velocity and the control input of the system, in the case of backstepping controller. Figure 7 shows the ball position, ball velocity, angle of the beam, angular velocity and the control input of the system, in the case of adaptive backstepping controller. Figure 8 shows the actual and estimated uncertain parameters of the system. It is clear from the figure that estimation errors are convergent,

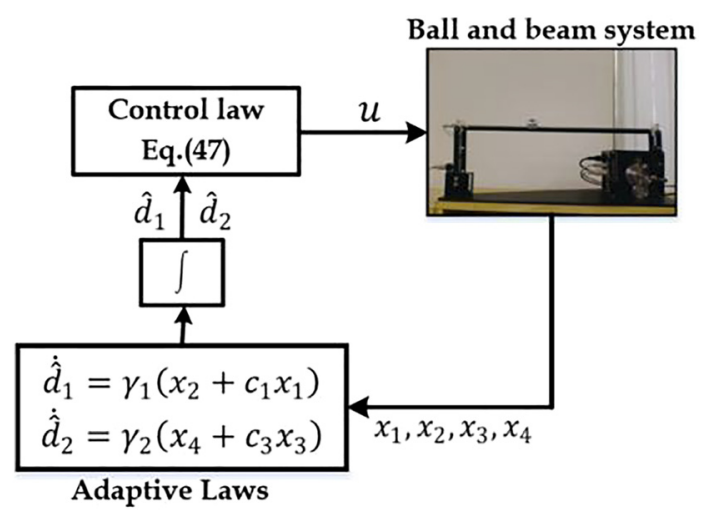

Fig. 3. Proposed adaptive control scheme 


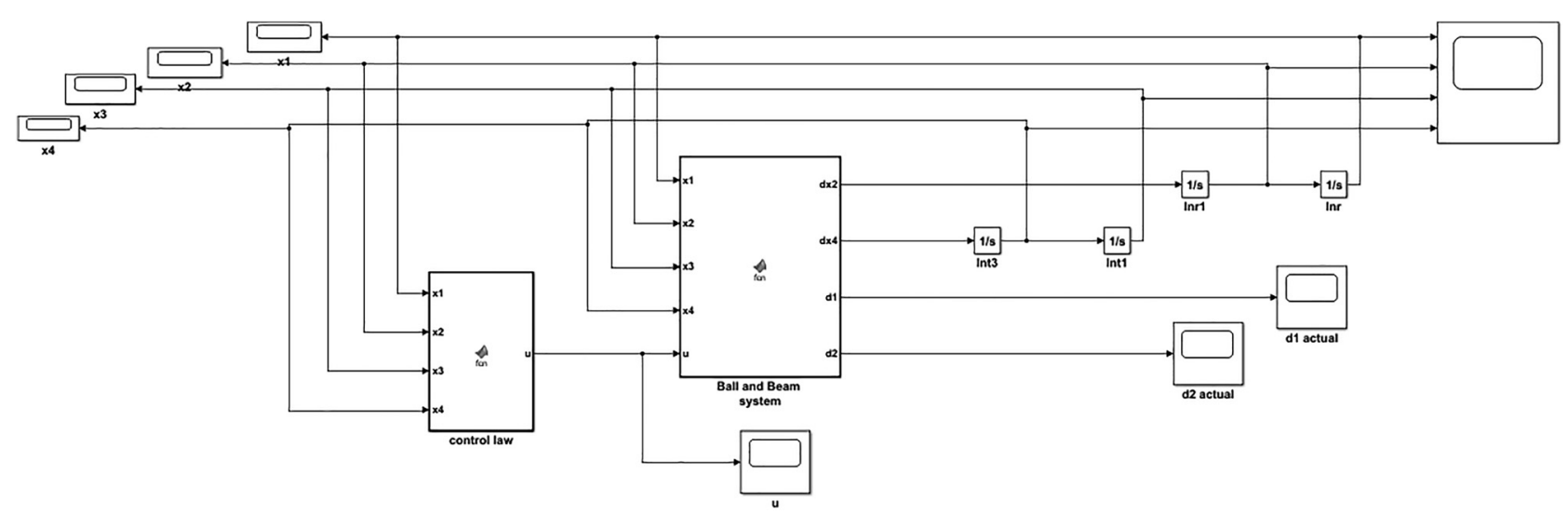

Fig. 4. Simulink/MATLAB block diagram for backstepping control design

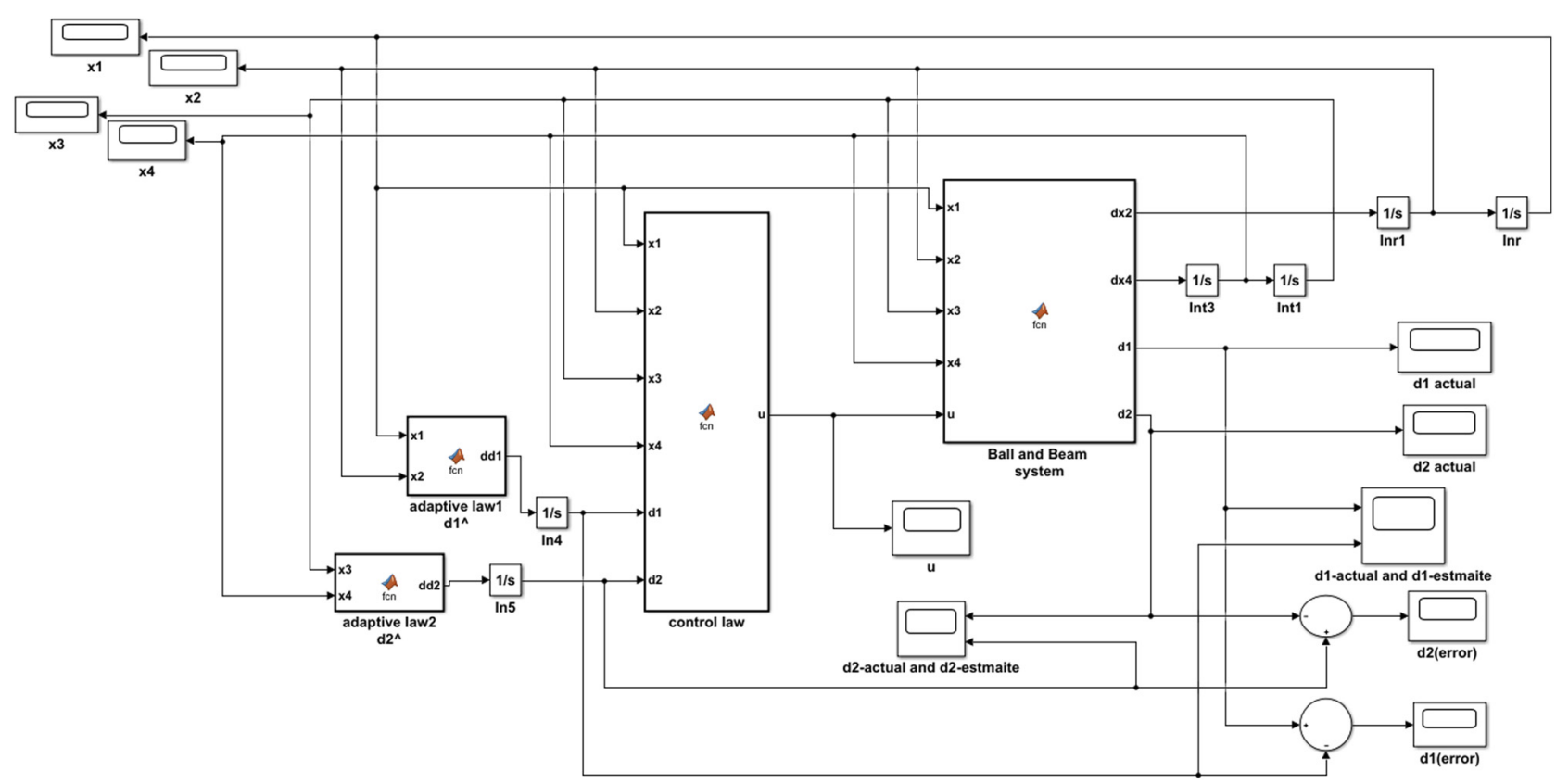

Fig. 5. Simulink/MATLAB block diagram for adaptive backstepping control design

which proves the conclusion reached by stability analysis. In addition, it can be seen in the presented results that the nonlinear adaptive backstepping design improves the system performance, both in transient and steady state, and also reduces the control effort. The values of the physical parameters are listed in Table 1.

The performance of both controllers is reported numerically in terms of ball velocity. Table 2 lists the transient characteristics of both classical and adaptive backstepping controllers. It is clear from the table that the dynamic performance due to adaptive controller is better than that based on classical controller.

\section{CONCLUSION}

The ball and beam platform has great educational attractivity because, despite the very simple mechanical mechanism, it has complex dynamic characteristics, such as nonlinearities and open loop instability. So, it is a good choice for the test and validation of modern control algorithms, which is the case of the adaptive backstepping technique proposed in this work for a nonlinear control system subjected to disturbances and model uncertainties.

The design of a nonlinear adaptive backstepping controller, applied to the ball position control in a dynamic ball and beam system, was presented in this paper. The simulated results showed that, compared to a traditional nonlinear backstepping controller, the adaptive backstepping improves the transient and steady state performance, and also reduces the control effort. In addition, the robustness to parameters uncertainties was verified and the design procedure was validated. In future work, the robustness against exogenous disturbances should be taken into account in the formulation of the adaptive control law. 


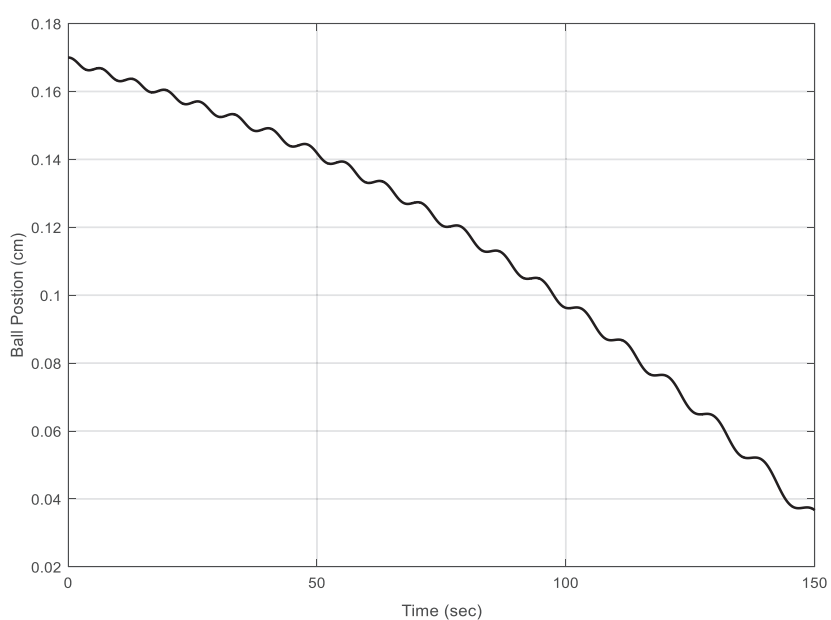

(a)

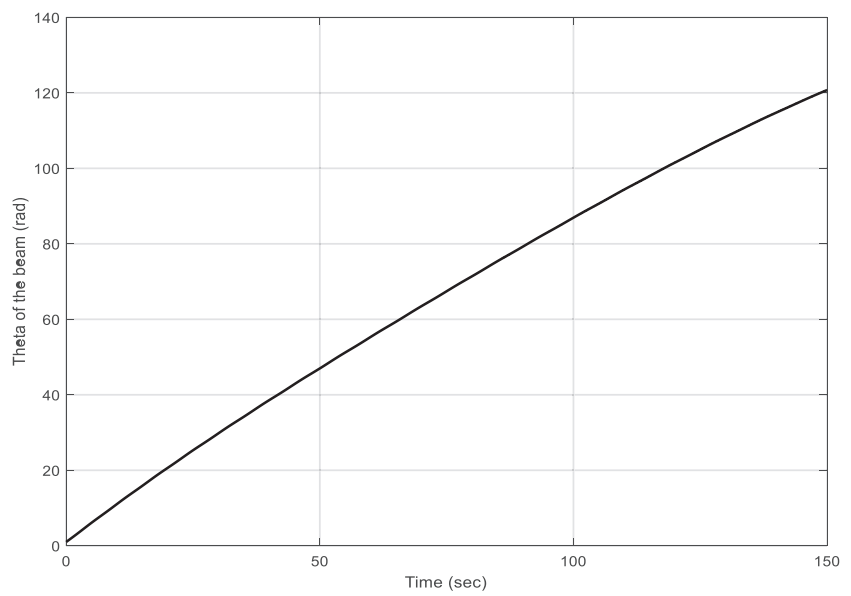

(c)

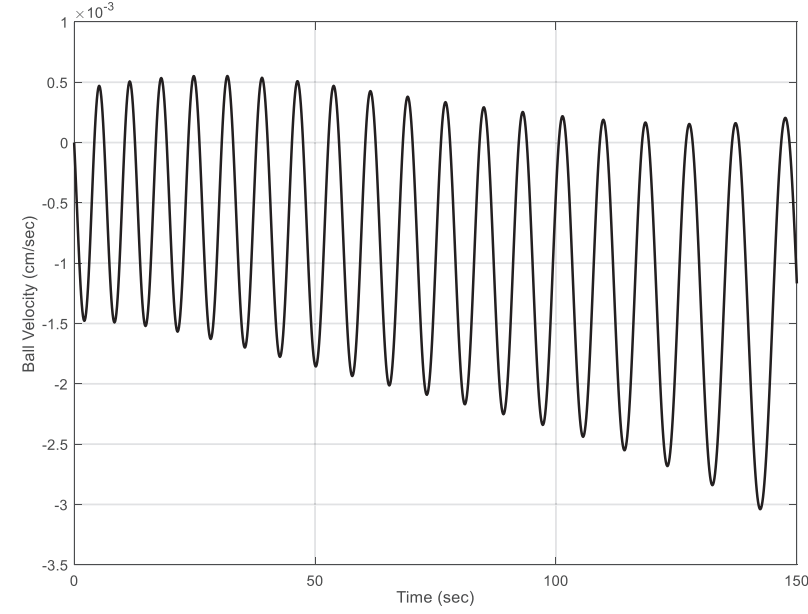

(b)

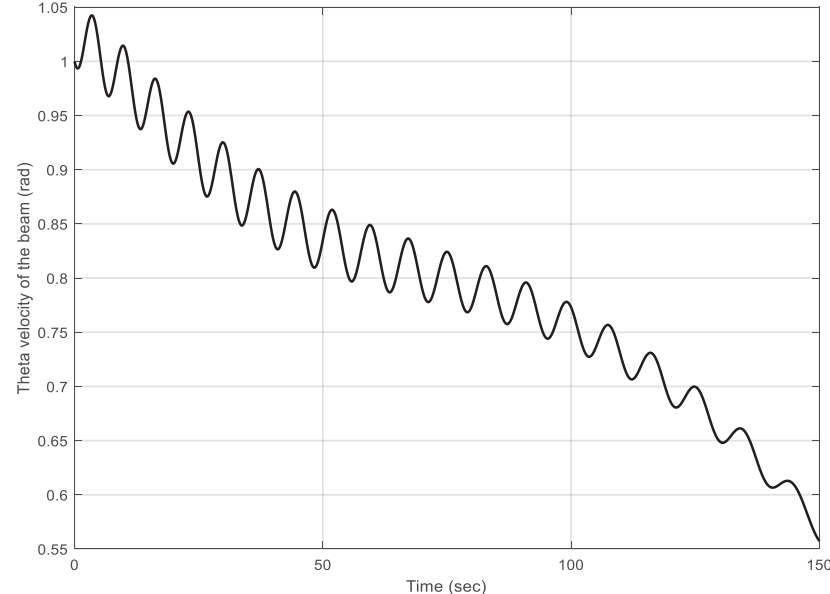

(d)

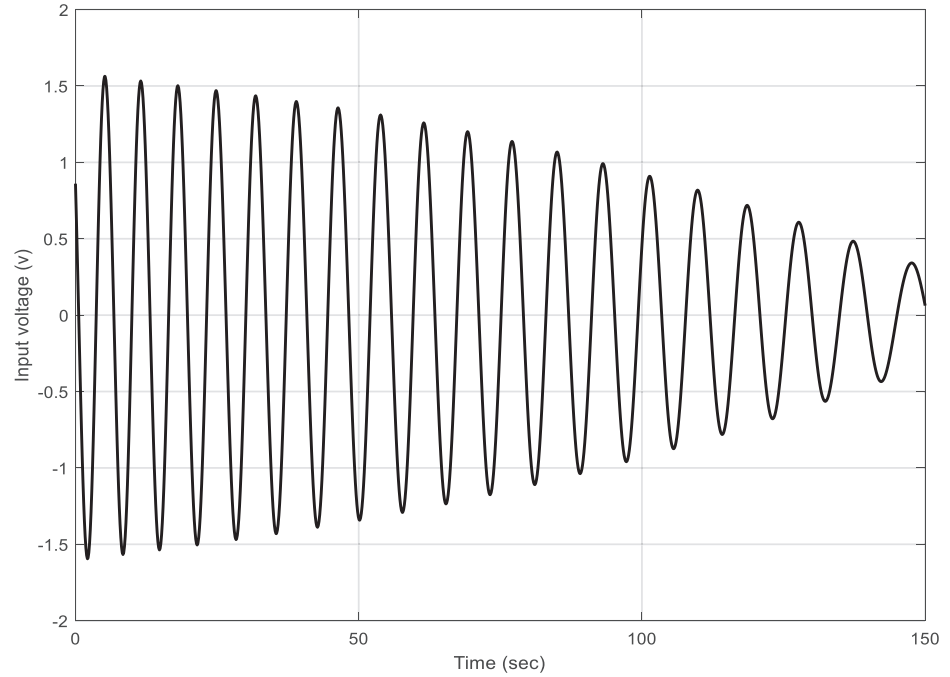

(e)

Fig. 6. Position of the ball, velocity of the ball, theta of the beam, theta velocity of the beam, input voltage $(u)$ 


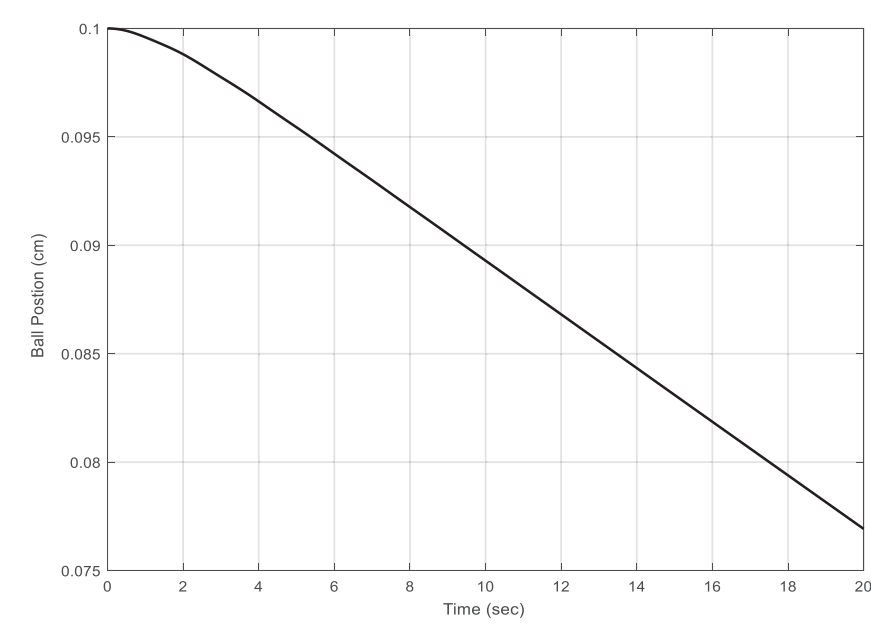

(a)

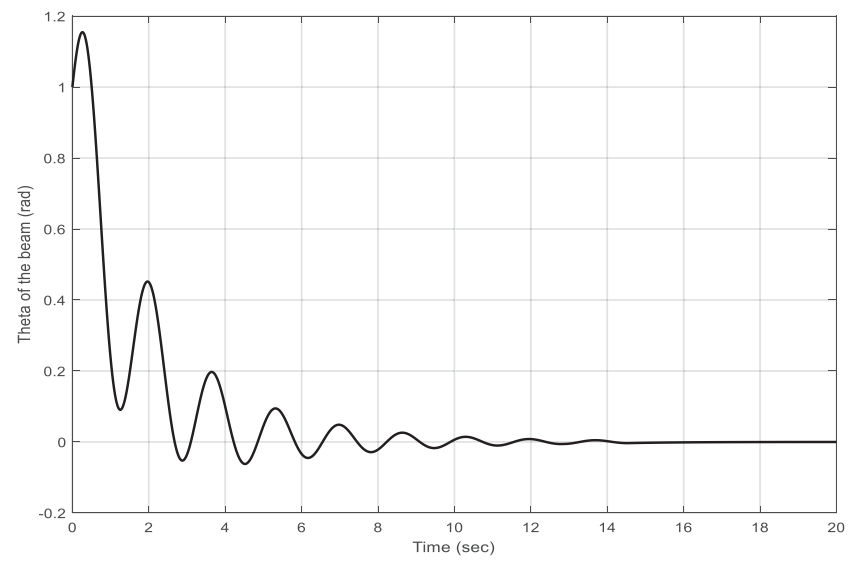

(c)

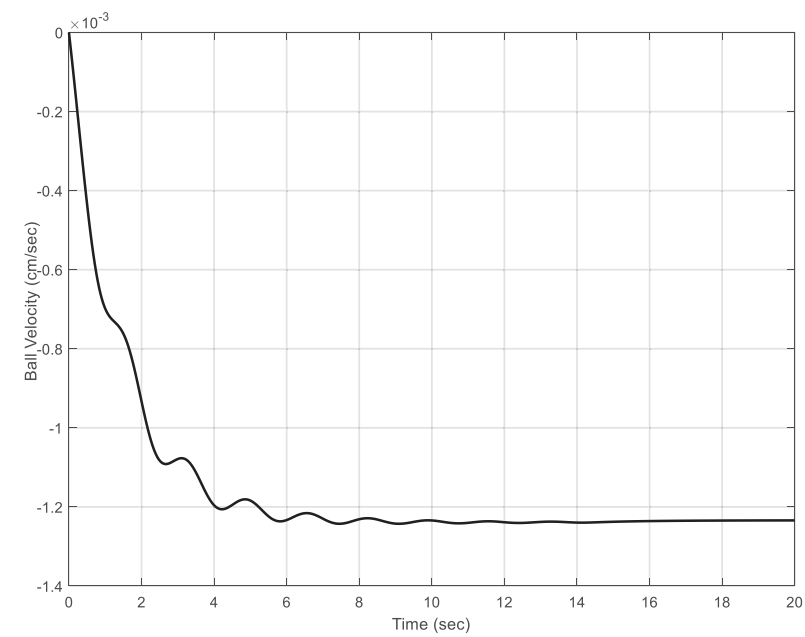

(b)

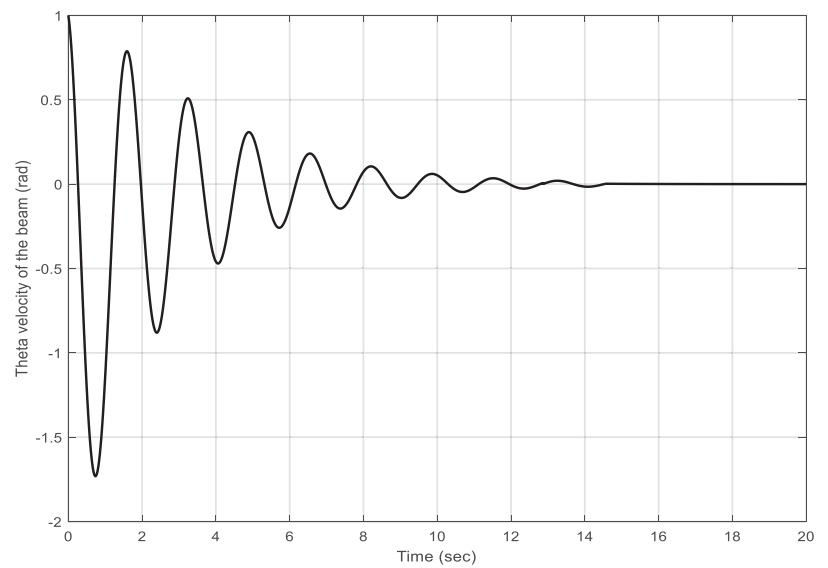

(d)

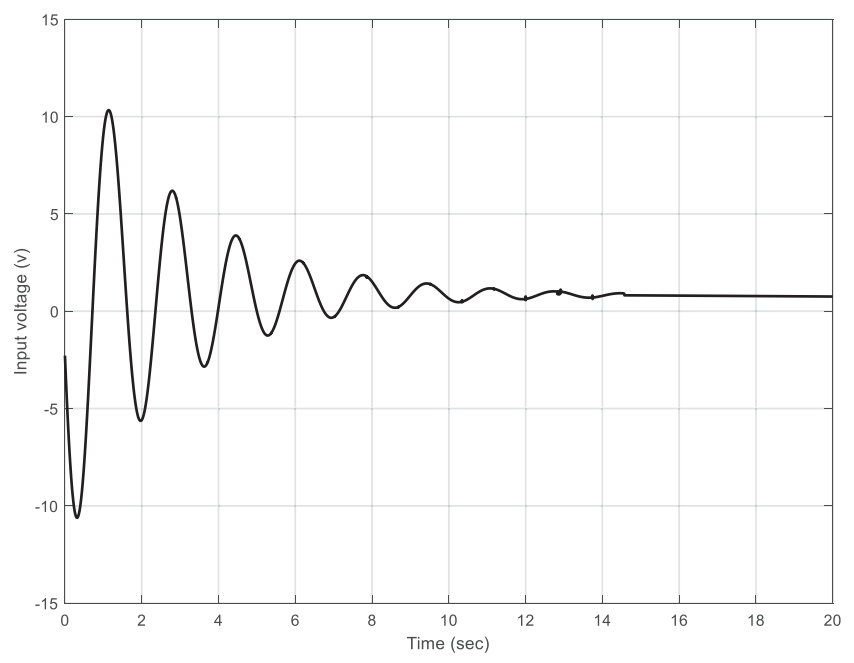

(e)

Fig. 7. Position of the ball, velocity of the ball, theta of the beam, theta velocity of the beam, input voltage $(u)$ 

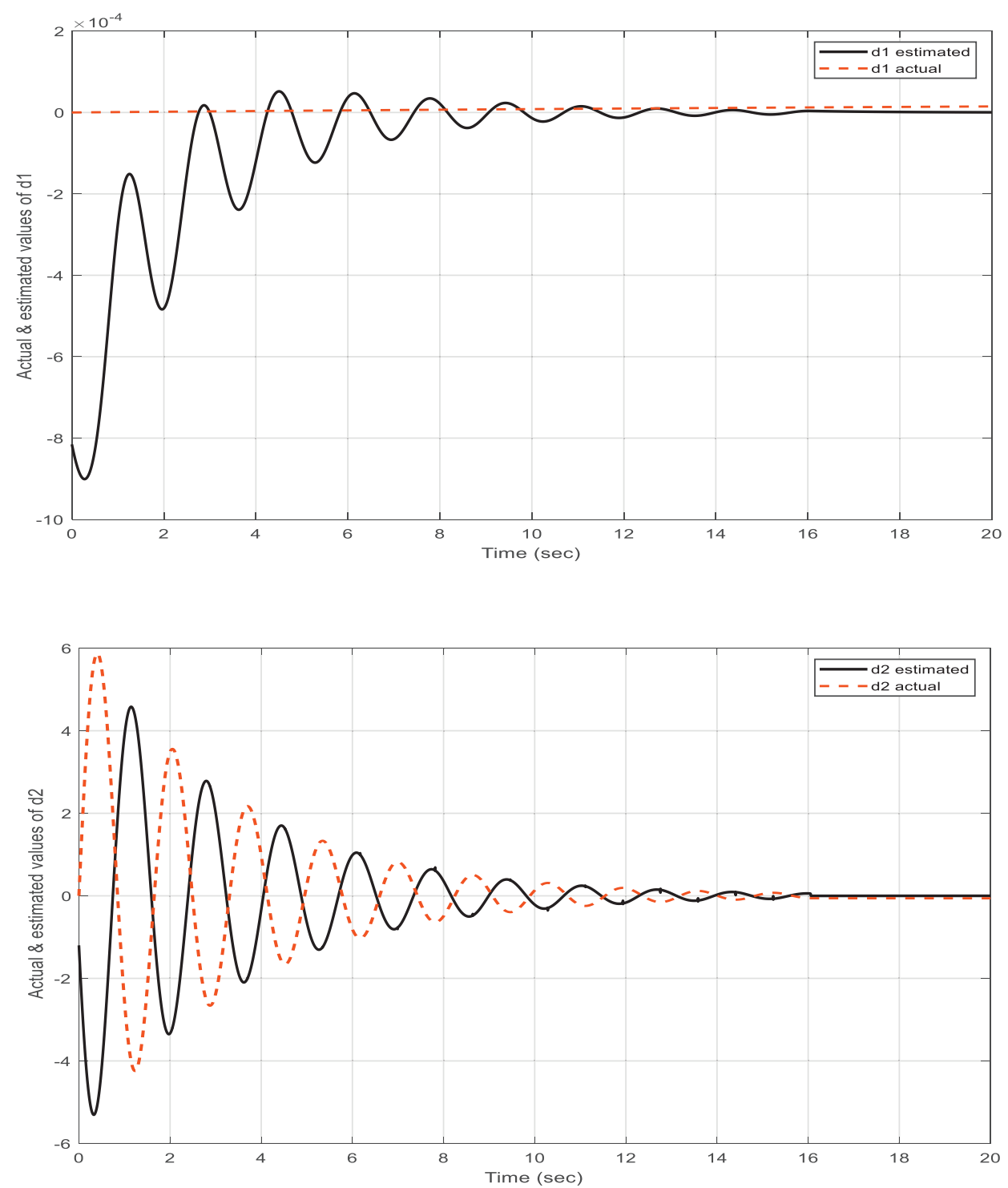

Fig. 8. The actual and estimated responses of $d_{1}$ and $d_{2}$

Table 1. Physical parameters of ball and beam system

\begin{tabular}{lcc}
\hline Symbol & Description & Value \\
\hline$g$ & Earth's gravitational constant $\left(\mathrm{m} / \mathrm{s}^{2}\right)$ & 9.8 \\
$m$ & Mass of the ball $(\mathrm{kg})$ & 0.064 \\
$R$ & Ball radius $(\mathrm{cm})$ & 1.27 \\
$I$ & Beam moment of inertia $\left(\mathrm{kg} \cdot \mathrm{m}^{2}\right)$ & $4.1290 \times 10^{-6}$ \\
$I_{b}$ & Ball moment of inertia $\left(\mathrm{kg} \cdot \mathrm{m}^{2}\right)$ & $2.25 \times 10^{-5}$ \\
$\mathrm{~V}$ & Rating input voltage & $12 \mathrm{v}$ \\
\hline
\end{tabular}

Table 2. Ball velocity comparison

\begin{tabular}{lcccc}
\hline & $\begin{array}{c}\text { Max. } \\
\text { overshot } \\
\text { Mp\% }\end{array}$ & $\begin{array}{c}\text { Settling } \\
\text { time }(\mathrm{s}) \\
\text { Ts }\end{array}$ & $\begin{array}{c}\text { Rise } \\
\text { time } \\
(\mathrm{s})\end{array}$ & $\begin{array}{c}\text { Steady- } \\
\text { state error }\end{array}$ \\
\hline $\begin{array}{c}\text { Controller types } \\
\begin{array}{c}\text { Backstepping } \\
\text { controller }\end{array}\end{array}$ & unstable & infinity & infinity & infinity \\
$\begin{array}{c}\text { Adaptive } \\
\text { backstepping } \\
\text { controller }\end{array}$ & $2 \%$ & $10 \mathrm{~s}$ & $7 \mathrm{~s}$ & $1.1 \mathrm{~cm} / \mathrm{s}$ \\
\hline
\end{tabular}

This study can be extended for future work if other control schemes are included to control the ball and beam system and to conduct comparison study in performance with the present control technique. One may use the following modern control methodologies for this purpose such as active disturbance control, super-twisting sliding mode control, projection adaptive sliding mode control, Interval type-2 Fuzzy logic control, etc [38-47].

\section{REFERENCES}

[1] M. Hamid and L. D. Elaheh, "Designing a fuzzy type-2 model based robust controller for ball and beam system," in 2016 IEEE International Symposium on Robotics and Intelligent Sensors (IRIS), 17-20 Dec. 2016.

[2] M. Ding, B. Liu, and L. Wang, "Position control for ball and beam system based on active disturbance rejection control," Syst. Sci. Control Eng. Open Access J., vol. 7, no. 1, pp. 97-108, 2019. 
[3] B. M. Hung, S. S. You, H. S. Kim, and T. W. Lim, "Embedded controller building for ball and beam system using optimal control synthesis," J. Eng. Sci. Technol., vol. 12, no. 6, pp. 1460-74, 2017.

[4] A. Y. Krasinskii, A. N. Il'ina, and E. M. Krasinskaya, "Modeling of the ball and beam system dynamics as a nonlinear mechatronic system with geometric constraint," Vestn. Udmurtsk. Univ. Mat. Mekh. Komp. Nauki, vol. 27, no. 3, pp. 414-30, 2017.

[5] A. A. Ezzabi, K. C. Cheok, and F. A. Alazabi, "A nonlinear backstepping control design for ball and beam system," in 2013 IEEE 56th International Midwest Symposium on Circuits and Systems (MWSCAS), Columbus, OH, USA, Aug. 4-7, 2013.

[6] A. M. Moghadam and S. Balochian, "Design of combined sliding mode controller backstepping using genetic algorithm," Hindawi Publishing Corporation J. Eng., vol. 2013, p. 6, 2013, Art no. 614803.

[7] A. A. A. Emhemed, "Stability analysis of fuzzy control for ball and beam system," Int. J. Fuzzy Logic Syst. (IJFLS), vol. 3, no. 1, January 2013.

[8] M. Keshmiri, A. F. Jahromi, A. Mohebbi, M. Hadi Amoozgar, and W.-F. Xie, "Modeling and control of ball and beam system using model based and non-model-based control approaches," Int. J. Smart Sensing Intell. Syst., vol. 5, no. 1, March 2012.

[9] M.-S. Koo, H.-L. Choi, and J.-T. Lim, "Adaptive nonlinear control of a ball and beam system using centrifugal force term," Int. J. Innovative Comput. Inf. Control, vol. 8, no. 9, September 2012.

[10] Y.-H. Chang, W.-S. Chan, C.-W. Chang, and C. W. Tao, "Adaptive fuzzy dynamic surface control for ball and beam system," Int. J. Fuzzy Syst., vol. 13, no. 1, pp. 1-7, March 2011.

[11] M. A. Rana, Z. Usman, and Z. Shareef, "Automatic control of ball and beam system using particle swarm optimization," in 12th IEEE International Symposium on Computational Intelligence and Informatics, Budapest, Hungary, Nov. 21-22, 2011.

[12] M. F. Rahmat, H. Wahid, and N. Abdul Wahab, "Application of intelligent controller in a ball and beam control system," Int. J. Smart Sensing Intell. Syst., vol. 3, no. 1, March 2010.

[13] N. B. Almutairi and M. Zribi, "On the sliding mode control of a ball on a beam system," Int. J. Nonlinear Dyn. Chaos Eng. Syst., vol. 59, no. 1-2, pp. 221-38, 2010.

[14] X. Li and W. Yu, "Synchronization of ball and beam systems with neural compensation," Int. J. Control Automation, Syst., vol. 8, no. 3, pp. 491-6, 2010.

[15] S. U. Din, Q. Khan, F. U. Rehman, and R. Akmeliawati, "Robust control of underactuated systems: Higher order integral sliding mode approach," Hindawi Publishing Corporation Math. Prob. Eng., vol. 2016, p. 11, 2016, Art no. 5641478.

[16] S. U. Din, Q. Khan, F. U. Rehman, and R. Akmeliawanti, "A comparative experimental study of robust sliding mode control strategies for underactuated systems," IEEE Access, vol. 6, pp. 1927-39, 2017.

[17] R. M. Hirschorn, "Incremental sliding mode control of the ball and beam," IEEE Trans. Automatic Control, vol. 47, no. 10, October 2002.

[18] P. H. Eaton, D. V. Prokhorov, and D. C. Wunsch, "Neurocontroller alternatives for fuzzy ball and beam systems with nonuniform nonlinear friction," IEEE Trans. Neural Networks, vol. 11, no. 2, Mar 2000.

[19] J. Hauser, S. Sastry, and P. Kokotovic, "Nonlinear control via approximation input output linearization: the ball and beam example," IEEE Trans. Automatic Control, vol. 37, no. 3, Mar 1992.

[20] W. Yu, "Nonlinear PD regulation for ball and beam system," Int. J. Electr. Eng. Educ., vol. 46, no. 1, pp. 59-73, January 2009.

[21] S.-K. Oh, H.-J. Jang, and W. Pedrycz, "The design of a fuzzy cascade controller for ball and beam system: a study in optimization with the use of parallel genetic algorithms," Eng. Appl. Artif. Intell., vol. 22, no. 2, pp. 261-71, March 2009.

[22] S.-K. Oh, H.-J. Jang, and W. Pedrycz, "Optimized fuzzy PD cascade controller: a comparative analysis and design," Simulation Model. Pract. Theor., vol. 19, no. 1, pp. 181-95, January 2011.

[23] M. Kazemia, J. Najafia, and M. B. Menhajb, "Fuzzy PD cascade controller design for ball and beam system based on an improved ARO technique," J. Comput. Robotics, vol. 5, no. 1, pp. 1-6, 2012.

[24] N. H. Jo, and J. H. Seo, "A state observer for nonlinear systems and its application to ball and beam system," IEEE Trans. Automatic Control, vol. 45, no. 5, pp. 968-73, May 2000.

[25] O. D. Montoya, W. Gil-González, and C. Ramírez-Vanegas, "Discrete-inverse optimal control applied to the ball and beam dynamical system: a passivity-based control approach," Symmetry, vol. 12 , no. $8,2020$.

[26] Y. Kim, S.-K. Kim, and C. K. Ahn, "Variable cut-off frequency observer-based positioning for ball-beam systems without velocity and current feedback considering actuator dynamics," IEEE Trans. Circuits Syst. Regular Pap., vol. 68, no. 1, January 2021.

[27] R. M. Kagami, G. K. da Costa, T. S. Uhlmann, L. A. Mendes, and R. Zanetti Freire, "A generic web lab control tuning experience using the ball and beam process and multi-objective optimization approach," Information, vol. 11, no. 3, 2020.

[28] C. Aguilar-Ibañez, M. S. Suarez-Castanon, and J. D. J. Rubio, "Stabilization of the ball on the beam system by means of the inverse Lyapunov approach," Hindawi Publishing Corporation, Math. Prob. Eng., vol. 2012, 2012, Art no. 810597.

[29] I. M. Mehedi, U. M. Al-Saggaf, R. Mansouri, and M. Bettayeb, “Two degrees of freedom fractional controller design: application to the ball and beam system," Measurement, vol. 135, pp. 13-22, 2018.

[30] M. Dinga, B. Liua, and L. Wanga, "Position control for ball and beam system based on active disturbance rejection control," Syst. Sci. Control Eng. Open Access J., vol. 7, no. 1, pp. 97-108, 2019.

[31] Quanser Innovative Edutech, Ball and Beam Laboratory Manual, Quanser Inc., 2012.

[32] A. J. Humaidi, M. R. Hameed, and A. H. Hameed, "Design of block-backstepping controller to ball and arc system based on zero dynamic theory," J. Eng. Sci. Technol., vol. 13, no. 7, pp. 2084-105, 2018.

[33] Y. Ma, A. Al-Dujaili, "An adaptive actuator failure compensation scheme for two linked 2WD mobile robots," IOP Conf. Series: J. Phys., vol. Conf. Series 783, 2017. https://doi.org/10.1088/17426596/783/1/012021.

[34] A. J. Humaidi, S. K. Kadhim, and A. S. Gataa, "Development of a novel optimal backstepping control algorithm of magnetic impeller-bearing system for artificial heart ventricle pump," Cybernet. Sys.-Inter. J., vol. 23, pp. 1-21, 2020. Available: https:// doi.org/10.1080/01969722.2020.1758467.

[35] A. J. Humaidi, and H. Mustafa, "Development of a new adaptive backstepping control design for a non-strict and under-actuated system based on a PSO tuner," Inform. J., vol. 10, no. 2, pp. 1-17, 2019. Available: https://doi.org/10.3390/info10020038. 
[36] A. J. Humaidi, and F.H. Alaq, "Particle swarm optimization-based adaptive super-twisting sliding mode control design for 2-degreeof-freedom helicopter," Meas. Control. J., vol. 52, no. (9-10), pp. 1403-19, 2019. Available: https://doi.org/10.1177/ 0020294019866863.

[37] A. J. Humaidi, K. I. Ibraheem, A. T. Azar, and M. E. Sadiq, "A new adaptive synergetic control design for single link robot arm actuated by pneumatic muscles," Entropy, vol. 22(7), no. 723, pp. 1-24, 2020. Available: https://doi.org/10.3390/e22070723.

[38] A. Al-Dujaili, Y. Ma, M. E. Najjar, and C. Vincent, "Actuator fault compensation in three linked $2 \mathrm{WD}$ mobile robots using multiple dynamic controllers," IFAC PapersOnline, vol. 50-1, pp. 13556-62, 2017.

[39] A. J. Humaidi, and A. H. Hameed, "PMLSM position control based on continuous projection adaptive sliding mode controller," Sys. Sci. Control Eng., vol. 6, no. 3, pp. 242-52, 2018. Available: https://doi.org/10.1080/21642583.2018.1547887.

[40] D.A. Pereira, A. Al-Dujaili, M. El Najjar, C. Vincent, and Y. Ma, "Actuator fault estimation and fault tolerant control in three physically-linked 2WD mobile robots," IFAC Papers Online, vol. 5124, pp. 709-16, 2018. Available: https://doi.org/10.1016/j.ifacol. 2018.09.653.

[41] A. J. Humaidi, M. B. Hussein, and H.H. Akram, "PSO-based active disturbance rejection control for position control of magnetic levitation system," 5th International Conference on Control, Decision and Information Technologies (CoDIT'18), Thessaloniki, Greece, pp. 922-8, 2018. https://doi.org/10.1109/CoDIT.2018.8394955.
[42] F. H. Alaq, A. J. Humaidi, and K. I. Ibraheem, "Robust supertwisting sliding control of PAM-actuated manipulator based on perturbation observer," Cogent Engineering, vol. 7, no. 1858393, pp. 1-30, 2021. Available: https://doi.org/10.1080/23311916.2020. 1858393.

[43] Q A Al-Dujaili, A Falah, A. J. Humaidi, D. A. Pereira, and K. I. Ibraheem, "Optimal super-twisting sliding mode control design of robot manipulator: Design and comparison study," Int. J. Adv. Robotic Sys., pp. 1-17, 2020. Available: https://doi.org/10.1177/ 1729881420981524.

[44] A. J. Humaidi, H. T. Najem, Q A Al-Dujaili, D. A. Pereira, and A. T. Azar, "Social spider optimization algorithm for tuning parameters in PD-like Interval Type-2 Fuzzy Logic Controller applied to a parallel robot," Meas. Control., vol. 54, no. 3-4, pp. 303-23, 2021. Available: https://doi.org/10.1177/0020294021997483.

[45] Q. A Al-Dujaili, C. Vincent, M. El Najjar, and Y. Ma, “Actuator fault compensation tracking control for multi linked 2WD mobile robots," 25th Mediterranean Conference on Control and Automation (MED), 2017. https://doi.org/10.1109/MED.2017.7984158.

[46] A. J. humaidi, H. M. Badr, and A. R. Ajil, "Design of active disturbance rejection control for single-link flexible joint robot manipulator," 22nd International Conference on System Theory, Control and Computing (ICSTCC), Sinaia, Romania, pp. 452-8, 2018.

[47] A. J. Humaidi, and A. I. Abdulkareem, "Design of augmented nonlinear PD controller of Delta/Par4-like robot," J. Cont. Sci. Eng., vol. 2019, pp. 1-11, 2019. Available: https://doi.org/10.1155/ 2019/7689673. 